\title{
Suberoylanilide hydroxamic acid, a histone deacetylase inhibitor, attenuates postoperative cognitive dysfunction in aging mice
}

\author{
Min Jia ${ }^{1}$, Wen-Xue Liu ${ }^{1}$, He-Liang Sun ${ }^{1}$, Yan-Qing Chang ${ }^{2}$, Jiao-Jiao Yang ${ }^{1,3,4}$, \\ Mu-Huo Ji ${ }^{1}$, Jian-Jun Yang ${ }^{1,3,4 *}$ and Chen-Zhuo Feng ${ }^{2 *}$ \\ ${ }^{1}$ Department of Anesthesiology, Jinling Hospital, School of Medicine, Nanjing University, Nanjing, China, ${ }^{2}$ Institute of Aging \\ Research, School of Medicine, Hangzhou Normal University, Hangzhou, China, ${ }^{3}$ Jiangsu Province Key Laboratory \\ of Anesthesiology, Xuzhou Medical College, Xuzhou, China, ${ }^{4}$ Jiangsu Province Key Laboratory of Anesthesia and Analgesia \\ Application Technology, Xuzhou, China
}

\section{OPEN ACCESS}

Edited by:

Benedict C. Albensi,

University of Manitoba, Canada

Reviewed by:

Mary M. Torregrossa,

University of Pittsburgh, USA

Mauro Costa-Mattioli,

Baylor College of Medicine, USA

*Correspondence:

Jian-Jun Yang,

Department of Anesthesiology Jinling Hospital, School of Medicine,

Naniing University,

305 East Zhongshan Road,

Nanjing 210002, China

yjyangjj@126.com;

Chen-Zhuo Feng,

Institute of Aging Research,

School of Medicine,

Hangzhou Normal University,

58 Haishu Road, Yuhang District,

Hangzhou 311121, China

fengchenzhuo@hotmail.com

Received: 25 June 2015

Accepted: 28 August 2015

Published: 23 September 2015

Citation:

Jia M, Liu W-X, Sun H-L, Chang Y-Q,

Yang J-J, Ji M-H, Yang J-J and

Feng C-Z (2015) Suberoylanilide

hydroxamic acid, a histone

deacetylase inhibitor, attenuates

postoperative cognitive dysfunction in

aging mice.

Front. Mol. Neurosci. 8:52

doi: 10.3389/fnmol.2015.00052
Postoperative cognitive dysfunction (POCD) is a recognized clinical entity characterized with cognitive deficits after anesthesia and surgery, especially in aged patients. Previous studies have shown that histone acetylation plays a key role in hippocampal synaptic plasticity and memory formation. However, its role in POCD remains to be determined. Here, we show that suberoylanilide hydroxamic acid (SAHA), a histone deacetylase inhibitor, attenuates POCD in aging Mice. After exposed to the laparotomy, a surgical procedure involving an incision into abdominal walls to examine the abdominal organs, 16- but not 3-month old male C57BL/6 mice developed obvious cognitive impairments in the test of long-term contextual fear conditioning. Intracerebroventricular (i.c.v.) injection of SAHA at the dose of ( $20 \mu \mathrm{g} / 2$ $\mu$ l) $3 \mathrm{~h}$ before and daily after the laparotomy restored the laparotomy-induced reduction of hippocampal acetyl-H3 and acetyl-H4 levels and significantly attenuated the hippocampus-dependent long-term memory (LTM) impairments in 16-month old mice. SAHA also reduced the expression of cleaved caspase-3, inducible nitric oxide synthase (iNOS) and N-methyl-D-aspartate (NMDA) receptor-calcium/calmodulin dependent kinase II (CaMKII) pathway, and increased the expression of brain-derived neurotrophic factor (BDNF), synapsin 1, and postsynaptic density 95 (PSD95). Taken together, our data suggest that the decrease of histone acetylation contributes to POCD and may serve as a target to improve the neurological outcome of POCD.

Keywords: postoperative cognitive dysfunction, aging, histone acetylation, neuroapoptosis, synaptic plasticity

Abbreviations: POCD, postoperative cognitive dysfunction; HATs, histone acetyltransferases; HDACs, histone deacetylases; SAHA, suberoylanilide hydroxamic acid; DMSO, dimethylsulfoxide; iNOS, inducible nitric oxide synthase; BDNF, brainderived neurotrophic factor; PSD95, postsynaptic density 95; NMDA, N-methyl-D-aspartate; CaMKII, calcium/calmodulin dependent kinase II; HE staining, Hematoxylin-eosin staining; PBS, phosphate-buffered saline; PFA, phosphate-buffered paraformaldehyde; STM, short-term memory; LTM, long-term memory; TBST, Tris-Buffered Saline Tween; Ac-H3K9, histone H3(acetyl K9); Ac-H3K14, histone H3(acetyl K14); Ac-H4K5, histone H4 (acetyl K5); Ac-H4K12, histone H4 (acetyl K12); Ac-H3, acetyl histone H3; Ac-H4, acetyl histone H4 (Lys5/8/12/16); GAPDH, genes glyceraldehyde-3-phosphate dehydrogenase; real-time PCR, real-time polymerase chain reaction; AD, Alzheimer's disease; LTD, long-term depression; LTP, long-term potentiation. 


\section{Introduction}

Postoperative cognitive dysfunction (POCD) is a cognitive progressive deterioration in memory and concentration following exposure to anesthesia and surgery (Amar et al., 1998; Terrando et al., 2011; Hovens et al., 2012). These cognitive deficits result in prolonged hospitalization and decreased quality of life (Moller et al., 1998). Tissue damage induced neuro-inflammation and altered reactivity of the immune system after operation are considered to play a major role in the development of POCD, which elicits neuron damages, affects synaptic function, and thereby induces cognitive impairments (Wan et al., 2007; Fidalgo et al., 2011). However, the molecular mechanisms underlying POCD remain largely to be determined.

Epigenetic dysregulation on the expression of key genes is widely involved in the etiology of brain disorders, including Alzheimer's disease (AD), Huntington's disease, Parkinson's disease, and Rubinstein-Taybi syndrome (Petrij et al., 1995; Kazantsev and Thompson, 2008; Chuang et al., 2009; Francis et al., 2009; Peleg et al., 2010; Gräff and Tsai, 2013). Histone acetylation is one of the most common forms of epigenetic modification, which is controlled by the balance between histone acetyltransferases (HATs) and histone deacetylases (HDACs; Fischer et al., 2010; Haggarty and Tsai, 2011; McQuown et al., 2011). In general, histone acetylation facilitates gene transcription, whereas histone deacetylation results in gene silencing (Fischer et al., 2010; Haggarty and Tsai, 2011; McQuown et al., 2011). A substantial body of evidence suggests that the dysregulation of histone acetylation contributes to the pathogenesis of neurodegenerative diseases, and targeted restoration of histone acetylation by HDAC inhibitors shows neuroprotective effects on neurodegenerative diseases (Petrij et al., 1995; Dash et al., 2010; Kilgore et al., 2010; Haettig et al., 2011; Ji et al., 2014).

The similar clinical symptoms has been revealed between POCD and neurodegenerative disorders (Wang et al., 2013; Luo et al., 2014; Xu et al., 2014). However, comparing with the studies of neurodegenerative diseases, the potential function of histone acetylation in POCD remains primarily unknown. Therefore, based on the pre-clinical animal mode of the laparotomy-induced cognitive deficits (Rosczyk et al., 2008; Barrientos et al., 2012; Hovens et al., 2014), which surgical procedure involving an incision into the abdominal wall to examine the abdominal organs, we investigated the role of histone acetylation and potential therapeutic effect of an HDAC inhibitor, suberoylanilide hydroxamic acid (SAHA), on POCD.

\section{Materials and Methods}

\section{Animals}

All animal experiments were carried out in accordance with the National Institutes of Health Guide for the Care and Use of Laboratory Animals, USA. The study protocol was approved by the Institutional Animal Care and Use Ethics Committee, Jinling Hospital, Nanjing University, Nanjing, China. The mice were purchased from The Animal Center of Jinling Hospital, Nanjing, China and efforts were made to minimize the number of animals used and their suffering. The mice were housed under specific pathogen-free conditions in a temperature-controlled room of $23 \pm 1^{\circ} \mathrm{C}$ on a 12-h light-dark cycle, with ad libitum access to food and water. Mice were allowed 7 days to acclimate to the laboratory conditions before experiments.

\section{Study Groups of Animals}

In the first set of experiments, the 3- and 16-month old male C57BL/6 mice were used. Thirty-two 3-month old mice weighing 25-32 g and thirty-two 16-month old mice weighing 33-40 g were randomly assigned to receiving laparotomy or sham surgery ( $n=16$ for each group). The experimental protocol was presented in Figure $1 \mathrm{~A}$.

In the second set of experiments with SAHA (a histone deacetylase inhibitor) treatment, sixty-four 16-month old male mice weighing 33-40 g were randomly assigned to the following four groups: Sham + Vehicle group, mice received vehicle treatment and sham surgery; Sham + SAHA group, mice received SAHA treatment and sham surgery; Laparotomy + Vehicle group, mice received vehicle treatment and laparotomy; and Laparotomy + SAHA group, mice received SAHA treatment and laparotomy ( $n=16$ for each group). The experimental protocol was presented in Figure 1B.

\section{Surgery}

The Laparotomy or sham surgery was performed as previously described (Rosczyk et al., 2008; Barrientos et al., 2012; Hovens et al., 2014). Anesthesia was induced with $1.5 \%$ isoflurane in $100 \%$ oxygen in mice and was still maintained with $1.5 \%$ isoflurane by mice anesthesia mask during the surgery procedure. After the abdominal region of mice was shaved and cleaned with iodophor disinfectant, a $1.5 \mathrm{~cm}$ vertical incision, approximately $0.5 \mathrm{~cm}$ below the lower right rib, was created. The viscera and musculature were vigorously manipulated by inserting a sterile probe into the body cavity and stretching the musculature. Intestine was then exteriorized and manipulated between the surgeon's thumb and forefinger. The intestines were then placed back into the peritoneal cavity. The surgeries were lasted for approximately $15 \mathrm{~min}$. After that, the peritoneal lining, muscle wall and the skin were closed with three dissolvable sutures and four silk thread sutures, respectively. The exterior wounds were dressed with polysporin to prevent potential infection. To eliminate the effect of hypoxia and acidosis to the experiment, both hypoxia and acidosis were analyzed by using arterial blood gas as we described before Li et al. (2014). Isoflurne anesthesia was stopped immediately for all groups of mice once the suture was in place. After recovery from anesthesia, the mice were placed back into their home cages with ad libitum access to food and water. For the sham surgery, mice were anesthetized, shaved, cleaned and the incision was sutured under isoflurane anesthesia for the same duration as those that the laparotomy surgical mice spent. Without manipulation of the viscera or musculature, the incision was closed and treated as described above. 


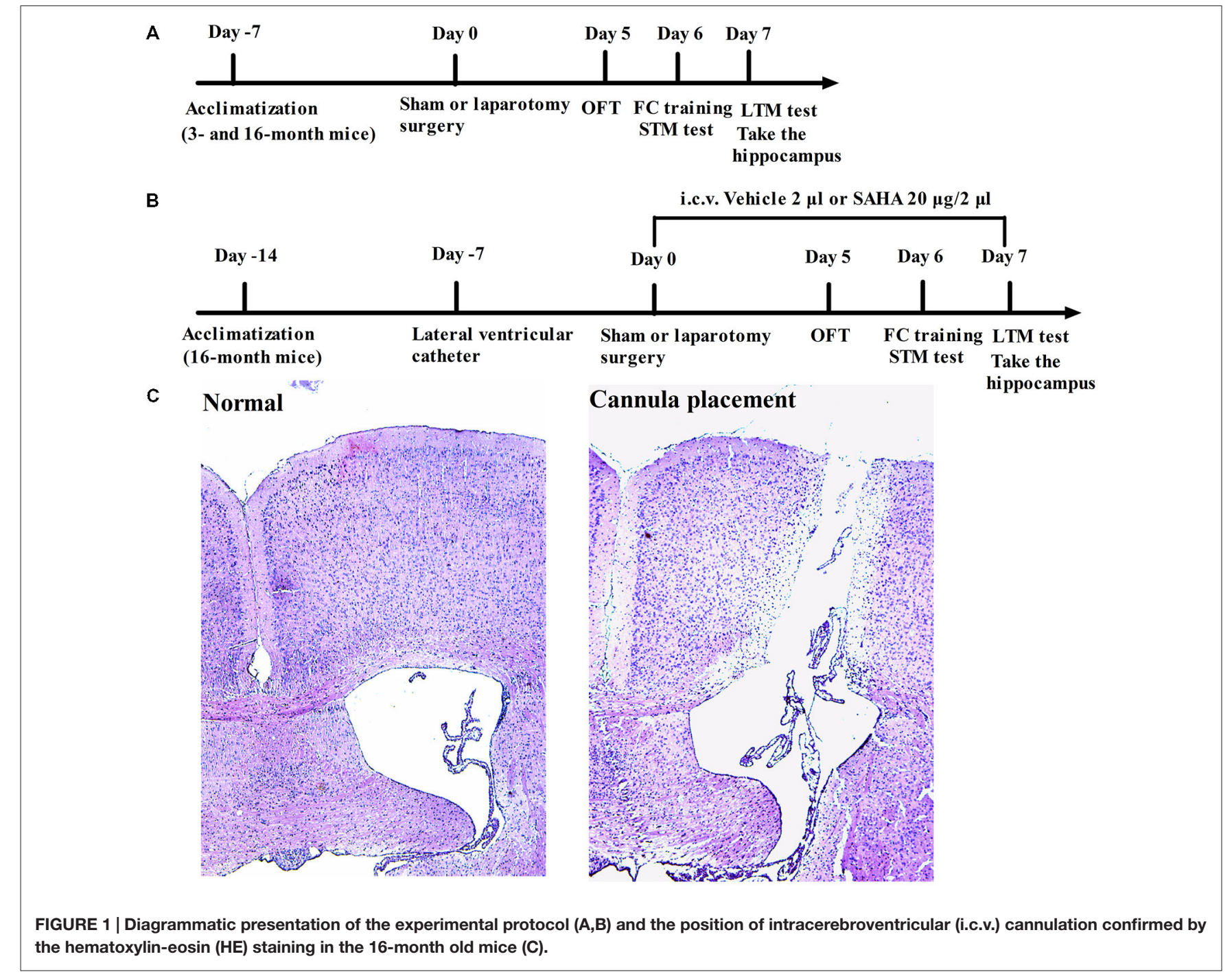

\section{Cannula Placement and SAHA Treatment}

Cannula placement was performed 7 days before the surgery (Figure 1C). In the second set of experiments, each mouse was stereotaxically implanted with 24-gauge, stainless steel guide cannula (RWD Life Science Co., Ltd, Shenzhen, China) under anesthesia with intraperitoneal injection of $50 \mathrm{mg} / \mathrm{kg} 2 \%$ pentobarbital sodium. The position of guide cannula was in the left lateral ventricle, which is $0.45 \mathrm{~mm}$ posterior to bregma, $1.08 \mathrm{~mm}$ lateral to bregma, and $2.50 \mathrm{~mm}$ deep to dura. Once the guide cannula was placed, it was fixed to skull with glass ionomer cement (Dental Materials Factory of Shanghai Medical instrument Co., Ltd, Shanghai, China). The cannula placements were verified by postmortem dissections of brain tissue, followed by hippocampus collections.

The dose and time point for SAHA treatment (S1047, Selleckchem, TX, USA) were designed according to the previous study, in which it was showed that the hippocampal histone acetylation levels peaked 3-h after the intracerebroventricular (i.c.v.) injection of SAHA in mice (Alarcón et al., 2004). SAHA was dissolved in $40 \%$ of dimethylsulfoxide (DMSO) diluted with saline. In the group of mice treated with SAHA, the dose of $20 \mu \mathrm{g}$ in $2 \mu \mathrm{l}$ was used through i.c.v. injection once daily for 7 days. The first dose was given at the time of 3-h before the laparotomy or sham surgery. For the vehicle controls, the same amount of $40 \%$ DMSO was used.

\section{Hematoxylin-Eosin (HE) Staining}

In our preliminary experiment, to ensure the fixed position of left lateral ventricle, 7 days after cannula placement, mice were anesthetized deeply with intraperitoneal injection of $50 \mathrm{mg} / \mathrm{kg}$ $2 \%$ pentobarbital sodium, and then perfused transcardially with $0.1 \mathrm{M}$ phosphate-buffered saline (PBS, $\mathrm{pH}$ 7.4), followed by $4 \%$ phosphate-buffered paraformaldehyde (PFA) for tissue fixation. The brain was removed, post-fixed in the same PFA solution for $12 \mathrm{~h}$ and sequentially immersed in 30\% sucrosephosphate-buffer solution for $24 \mathrm{~h}$ at $4^{\circ} \mathrm{C}$. Coronal 5 - $\mu \mathrm{m}$-thick 
cryostat sections were cut for the routine hematoxylin-eosin (HE) staining.

Each section was stained in Harris's hematoxylin solution for $8 \mathrm{~min}$, differentiated in $1 \%$ acid alcohol for $30 \mathrm{~s}$. After rinsing in $95 \%$ alcohol, the slides were counterstained in eosin-phloxine B solution for $45 \mathrm{~s}$. After being dehydrated in a graded series of ethanol and cleared in xylene solutions, the sections were mounted for observation under a light microscope (Olympus BX53F, Tokyo, Japan).

\section{Open Field Test}

All behavioral procedures were performed during the light phase of the cycle between 10:00 A.M. and 4:00 P.M. in a sound-isolated room. Five days after the laparotomy, the mice were subjected to the open field test. The open field apparatus was positioned in a dimly lit room and consisted of a white Plexiglas chamber $(40 \mathrm{~cm} \times 40 \mathrm{~cm}$ with walls $40 \mathrm{~cm}$ high). Each mouse was placed at the center of the arena and left to explore the whole field for $5 \mathrm{~min}$ of recording by using the video tracking system (XR-XZ301, Shanghai Softmaze Information Technology Co. Ltd, Shanghai, China). The total distance traveled and the time spent in the center was measured as the parameter of anxiolytic behavior. Between each test, the surface of the arena was thoroughly cleaned with $75 \%$ alcohol to avoid the presence of olfactory cues. Tests were recorded by a person who was blinded to the grouping of mice.

\section{Fear Conditioning Test}

On the sixth day after the laparotomy, mice were subjected to fear conditioning test by using the fear conditioning paradigm (XR-XC404, Shanghai Softmaze Information Technology Co. Ltd, Shanghai, China). A mouse was placed in a conditioning training chamber $(30 \mathrm{~cm} \times 30 \mathrm{~cm}$ with walls $45 \mathrm{~cm}$ high) enclosed by a soundproof box with a camera fixed on top. After a $3 \mathrm{~min}$ baseline exploratory period in the chamber, mice received one tone $(30 \mathrm{~s}, 70 \mathrm{~dB}, 3 \mathrm{kHz})$-foot-shock $(2 \mathrm{~s}$, $0.75 \mathrm{~mA}$ ) pairing. The foot-shock was carried out at the last $2 \mathrm{~s}$ of tone stimulation. Afterward, the mice were left in the conditioning box for additional $30 \mathrm{~s}$ before being returned to their home cage. Two hours after the training session, one batch of mice was place again in the training chamber and subjected to the short-term memory (STM) test. During a period of $5 \mathrm{~min}$ in the absence of tone and foot shock to test contextual fear conditioning to evaluate hippocampusdependent memory, the freezing behavior of each mouse was scored every $5 \mathrm{~s}$. Two hours after the contextual fear conditioning test, the mice were placed to a novel chamber for the cued (tone) fear conditioning test to evaluate amygdaladependent memory. After a $3 \mathrm{~min}$ exploratory period in the new chamber, a training tone $(30 \mathrm{~s}, 70 \mathrm{~dB}, 3 \mathrm{kHz})$ was applied for another $3 \mathrm{~min}$ and freezing behavior was scored during this tone period. The long-term memory (LTM) was performed at the time 24-h after training session and another batch of mice were used. Between each test, the chamber was thoroughly cleaned with $75 \%$ alcohol to avoid the presence of olfactory cues. The fear conditioning was administered and evaluated by a person blinded to the group assignment of mice.

\section{Preparation of Protein Extracts}

Two hours after the LTM test, mice were sacrificed and the hippocampus was harvested. The samples for measuring histone acetylation were prepared as described before Kilgore et al. (2010). Briefly, each sample was homogenized in the buffer containing $50 \mathrm{mM}$ Tris- $\mathrm{HCl}, \mathrm{pH} 7.5,25 \mathrm{mM} \mathrm{KCl}, 250 \mathrm{mM}$ sucrose, $2 \mathrm{mM}$ sodium butyrate, $1 \mathrm{mM}$ sodium orthovanadate, $0.5 \mathrm{mM}$ PMSF and $1 \times$ protease inhibitor cocktail (sigma, MO, USA). After centrifuge at $7700 \times \mathrm{g}$ for $1 \mathrm{~min}$ at $4^{\circ} \mathrm{C}$ to pellet nuclei, $0.4 \mathrm{~N} \mathrm{H}_{2} \mathrm{SO}_{4}$ was added to the pellet used for separating the histones. Then trichloroacetic acid with $10 \mathrm{mM}$ sodium deoxycholate was added to supernatant to precipitate histone and incubate on ice for $30 \mathrm{~min}$. After centrifuge at $14000 \times \mathrm{g}$ for $30 \mathrm{~min}$ at $4^{\circ} \mathrm{C}$, the pellet of histone was washed once by acidified acetone and then resuspended in $10 \mathrm{mM}$ Tris$\mathrm{HCl}, \mathrm{pH}$ 8.0.

For measuring the proteins of inducible nitric oxide synthase (iNOS), brain-derived neurotrophic factor (BNDF), synapsin 1, PSD-95, NR2A, NR2B, calcium/calmodulin dependent kinase II (CaMKII $\alpha$ ), and CaMKII $\beta$, Radio-Immunoprecipitation Assay (RIPA) buffer containing $1 \times$ protease inhibitor cocktail was used. Homogenates were centrifuged at $13000 \times \mathrm{g}$ at $4^{\circ} \mathrm{C}$ for $10 \mathrm{~min}$ and the supernatants were collected for western blot.

\section{Western Blot}

Approximately $1 \mu \mathrm{g}$ of histone protein or $50 \mu \mathrm{g}$ of total protein per lane was separately by polyacrylamide gels and then transferred to a polyvinylidene difluoride membrane. After being incubated in blocking buffer of $5 \%$ non-fat milk in Tris-Buffered Saline Tween (TBST), membranes were incubated overnight in each primary antibody at $4^{\circ} \mathrm{C}$. The primary antibodies used were anti-histone H3 (1:900; Cell Signaling, MA, USA), anti-histone H4 (1:900; Cell Signaling, MA, USA), anti-acetyl histone H3 (1:800; Merck Millipore, Darmstadt, Germany), anti-acetyl histone H4 (Lys5/8/12/16; 1:800; Merck Millipore, Darmstadt, Germany), anti-histone H3 (acetyl K9; 1:800; Abcam, MA, UK), anti-histone H3 (acetyl K14; 1:800; Merck Millipore, Darmstadt, Germany), anti-histone H4 (acetyl K5; 1:800; Abcam, MA, UK), antihistone H4 (acetyl K12; 1:900; Abcam, MA, UK), antiCleaved Caspase-3 (1:900; Cell Signaling, MA, USA), anti-iNOS (1:2000; ANBO, CA, USA), anti-BDNF (1:1500; Santa Cru, CA, USA), anti-Synapsin 1 (1:2500; Merck Millipore, Darmstadt, Germany), anti-postsynaptic density 95 (PSD95) (1:1500; Abcam, MA, UK), anti-NMDAR2A (1:1000; Abcam, MA, UK), anti-NMDAR2B (1:1000; Abcam, MA, UK), anti-CaMKII $\alpha$ (1:1000; Abcam, MA, UK), anti-CaMKII $\beta$ (1:1000; Abcam, MA, UK). Membranes were washed with TBST and incubated with appropriate secondary antibodies (goat anti-rabbit or goat anti-mouse; Santa Cru, CA, USA). Protein bands were visualized by using enhanced chemiluminescence method and quantitatively analyzed with Image J Quant Software (NIH, Bethesda, MD, USA). The densities of histone acetylation bands were normalized to those of histone from the same 
sample. The results from various experimental conditions were normalized to the data of mice in the Sham + Vehicle group.

\section{Real-Time PCR}

Real-time polymerase chain reaction (Real-time PCR) was performed as described previously (Feng et al., 2011). Total RNA was extracted from hippocampus of mouse using RNeasy micro kit (Qiagen, Valencia, CA, USA). Primers for real-time PCR were designed based on the reported sequence of mouse gene iNOS, BDNF, synapsin 1, PSD95, NR2A, NR2B, CaMKII $\alpha$, and CaMKII $\beta$ and designed by OligoPerfect Designer. The primers in conserved coding region were preferred, if the gene has various transcripts. The sequences of the primers were detailed in Table 1. Quantitative PCRs were carried out in triplicate using each cDNA sample that was equivalent to $50 \mathrm{ng}$ of stating total RNA. SYBR Green Quantitative PCR protocol was performed by using iQ SYBR Green Supermix (Bio-rad, CA, USA) in the Bio-Rad CFX96 real-time detection system (Biorad, CA, USA). To account for the possible differences in staring cDNA, quantitative PCR of the housekeeping genes glyceraldehyde-3-phosphate dehydrogenase (GAPDH) was also carried out for each sample. After PCR reaction, samples were subjected to a temperature ramp (from $70-95^{\circ} \mathrm{C}, 2^{\circ} \mathrm{C} / \mathrm{s}$ ) with continuous fluorescence monitoring for melting curve analysis. For each PCR product, a single narrow peak was obtained by melting curve analysis at the specific temperature. The relative amount of mRNA in each sample was determined using the comparative threshold cycle method and then normalized those of housekeeping gene GAPDH.

\section{Statistical Analysis}

Data are presented as the mean \pm S.E.M. and analyzed by the Statistical Product for Social Sciences (SPSS; version 17.0, IL, USA). The difference among groups was determined by twoway analysis of variance followed by Bonferroni's post hoc test. Age and surgery type, or surgery type and drug treatment, were considered as two independent factors. The $P$ values of age, surgery type, drug and interaction of factors were presented by $P_{\text {age }}, P_{\text {surg }}, P_{\text {drug }}$ and $P_{\text {int }}$ respectively. A $P$ value $<0.05$ was regarded as statistical significance.

\section{Results}

\section{Laparotomy Induced the Hippocampus- Dependent Long-Term Cognitive Impairments and Down-Regulation of Hippocampal Acetyl-H3 and Acetyl -H4 Levels in the 16- but not the 3-Month Old Mice}

To investigate the difference of POCD between adult and aging mice, laparotomy or sham surgery was performed on the 3- and 16-month old mice. Neither the 3- nor the 16month old mice had significant difference in the total distance traveled $\left(P_{\text {age }}=0.804, F_{\text {age }(1,28)}=0.0626 ; P_{\text {surg }}=0.982\right.$, $\left.F_{\text {surg }(1,28)}=0.00053 ; P_{\text {int }}=0.913, F_{\text {int }(1,28)}=0.00761\right)$ or time spent in the center $\left(P_{\text {age }}=0.855, F_{\text {age }(1,28)}=0.0338\right.$; $\left.P_{\text {surg }}=0.839, F_{\text {surg }(1,28)}=0.0421 ; P_{\text {int }}=0.913, F_{\text {int }(1,28)}=0.0122\right)$ after the laparotomy or sham surgery (Figures 2A,B). Then we used fear conditioning test to determine the associative memory. The laparotomy did not induce the acquirement of associative memory during the training session of prestimulation $\left(P_{\text {age }}=0.957, F_{\text {age }(1,28)}=0.00295 ; P_{\text {surg }}=0.985\right.$, $\left.F_{\text {surg }(1,28)}=0.000353 ; P_{\text {int }}=0.843, F_{\text {int }(1,28)}=0.0398\right)$ or poststimulation $\left(P_{\text {age }}=0.825, F_{\text {age }(1,28)}=0.0498 ; P_{\text {surg }}=0.990\right.$, $F_{\text {surg }(1,28)}=0.000176 ; P_{\text {int }}=0.948, F_{\text {int }(1,28)}=0.00432 ;$ Figure 2C) . In the STM test, no significant difference was found in the context $\left(P_{\text {age }}=0.506, F_{\text {age }(1,28)}=0.454 ; P_{\text {surg }}=0.920\right.$, $\left.F_{\text {surg }(1,28)}=0.0103 ; P_{\text {int }}=0.994, F_{\text {int }(1,28)}=0.0000547\right)$ or tone test $\left(P_{\text {age }}=0.593, F_{\text {age }(1,28)}=0.293 ; P_{\text {surg }}=0.925\right.$, $\left.F_{\text {surg }(1,28)}=0.00893 ; P_{\text {int }}=0.916, F_{\text {int }(1,28)}=0.0113\right)$ among the four groups (Figure 2D). However, in the LTM test, the laparotomy led to a shorter freezing time in the context $\left(P_{\text {age }}=0.003, F_{\text {age }(1,28)}=10.750 ; P_{\text {surg }}=0.017, F_{\text {surg }(1,28)}=6.396 ;\right.$ $\left.P_{\text {int }}=0.025, F_{\text {int }(1,28)}=5.583\right)$ but not in the tone test $\left(P_{\text {age }}=0.301, F_{\text {age }(1,28)}=1.113 ; P_{\text {surg }}=0.737, F_{\text {surg }(1,28)}=0.115 ;\right.$ $\left.P_{\text {int }}=0.736, F_{\text {int }(1,28)}=0.116\right)$ compared with the sham surgery in 16-month, but not 3-month old mice (Figure 2E).

We next examined the levels of acetyl-H3 and acetyl-H4 that are deeply involved in neurodegeneration diseases (Guan et al., 2009; Ricobaraza et al., 2009; Castellano et al., 2012). We found that the cognitive impairments in the 16-month old mice was accompanied with a decreased level of hippocampal acetyl-H3 $\left(P_{\text {age }}=0.034, F_{\text {age }(1,8)}=6.485 ; P_{\text {surg }}=0.007, F_{\text {surg }(1,8)}=12.971 ;\right.$ $\left.P_{\text {int }}=0.013, F_{\text {int }(1,8)}=10.043\right)$ and acetyl-H4 $\left(P_{\text {age }}=0.020\right.$, $F_{\text {age }(1,8)}=8.301 ; P_{\text {surg }}=0.047, F_{\text {surg }(1,8)}=5.499 ; P_{\text {int }}=0.049$,

TABLE 1 | The sequence of primers for real-time PCR analysis.

\begin{tabular}{|c|c|c|c|}
\hline Genes & Forward primers $\left(5^{\prime}-3^{\prime}\right)$ & Reverse primers $\left(5^{\prime}-3^{\prime}\right)$ & Accession number \\
\hline iNOS & GGATTGTCCTACACCACACCAA & ATCTCTGCCTATCCGTCTCGTC & NM_010927 \\
\hline BDNF & AGCTGAGCGTGTGTGACAGT & ACCCATGGGATTACACTTGG & NM_007540 \\
\hline Synapsin 1 & GCTGGAATCCCCAGTGTAAA & AGTTCCACGATGAGCTGCTT & NM_013680 \\
\hline PSD95 & CCCCAACATGGACTGTCTCT & АСТССАТСТСССССТСТGTT & NM_007864 \\
\hline NR2A & СТCTGATAATCCTाTССТCСAC & GACCGAAGATAGCTGTCATTTACT & NM_008170 \\
\hline NR2B & TCCATCAGCAGAGGTATCTACAG & CCGTTGACTCCAGACAGGTT & NM_008171 \\
\hline CaMKIl $\alpha$ & GCCTCAGTCCTCCTGTGAAG & АСТССТСТТСССАСССАСТТ & NM_009792 \\
\hline $\mathrm{CaMKII} \beta$ & ATCGCCACCGCCATGGCCAC & GGTGATCTCTGGCCGACAGCT & NM_001174053 \\
\hline GAPDH & ACCCAGAAGACTGTGGATGG & CACATTGGGGGTAGGAACAC & NM_001289726 \\
\hline
\end{tabular}




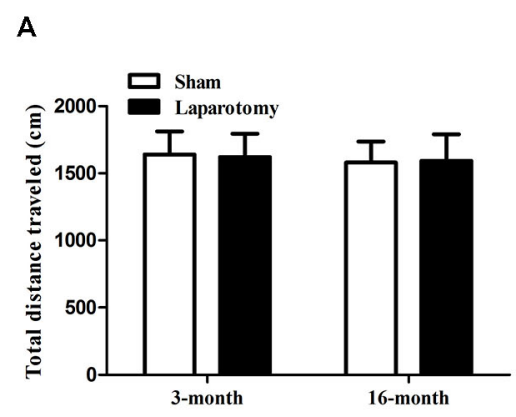

B

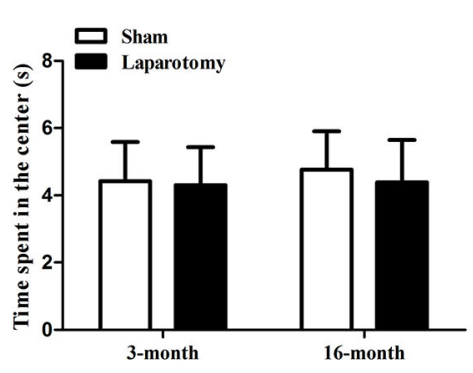

$\mathbf{E}$

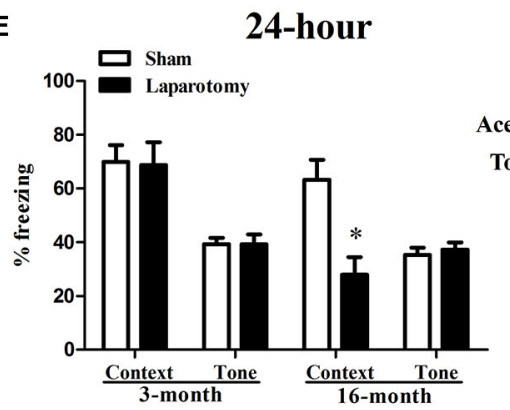

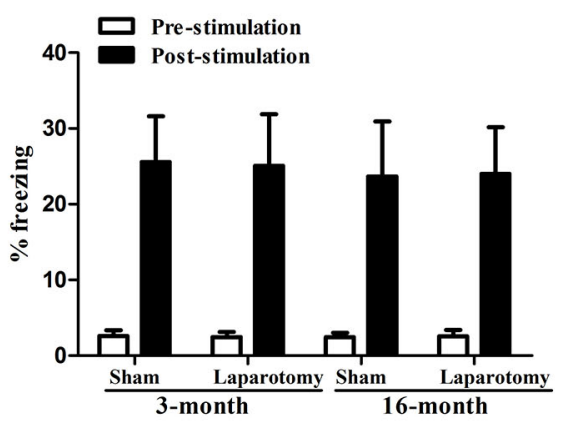
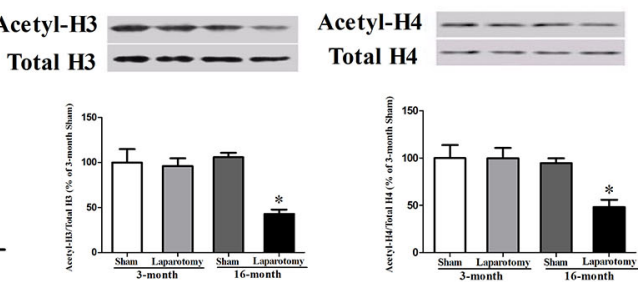

FIGURE 2 | Impact of the cognition and histone acetylation in the 3- and 16-month old mice after surgery. (A,B) Performance of total distance traveled and time spent in the center during the open field test. Data are presented as the mean \pm S.E.M. $(n=16)$. (C) Performance of freezing time during the fear conditioning training session. Data are presented as the mean \pm S.E.M. $(n=16)$. (D,E) Performance during fear conditioning tests 2- or 24-h after laparotomy. Data are presented as the mean \pm S.E.M. $(n=8)$. (F) The acetylation level of histone $\mathrm{H} 3$ and $\mathrm{H} 4$ in the 3- or 16-month-old mice after laparotomy. Results are mean \pm S.E.M. $(n=3) .{ }^{*} p<0.05$ compared with the 16-month old mice subjected to sham surgery.

$\left.F_{\text {int }(1,8)}=5.359\right)$, whereas the 3 -month old mice whose memory were not damaged did not show such a reduction (Figure 2 F).

\section{SAHA Ameliorated the Hippocampus-Dependent Long-Term Cognitive Impairments in the 16-Month Old Mice Exposed to the Laparotomy}

The poor hippocampus-dependent LTM with histone acetylation down-regulation in the 16-month old mice exposed to the surgery guided us to further investigate the effect of SAHA on these mice. The results didn't showed any significant differences in the total distance traveled $\left(P_{\text {surg }}=0.984, F_{\text {surg }(1,60)}=0.000388 ; P_{\text {drug }}=0.955\right.$, $\left.F_{\text {drug( }(1,60)}=0.00318 ; P_{\text {int }}=0.847, F_{\text {int }(1,60)}=0.0375\right)$, time spent in the center $\left(P_{\text {surg }}=0.676, F_{\operatorname{surg}(1,60)}=0.177 ; P_{\text {drug }}=0.904\right.$, $\left.F_{\text {drug(1,60) }}=0.0148 ; P_{\text {int }}=0.899, F_{\text {int }(1,60)}=0.0163\right)$, or ability of memory acquirement when calculating the freezing time in the pre-stimulation $\left(P_{\text {surg }}=0.984, F_{\text {surg }(1,60)}=0.000388\right.$; $\left.P_{\text {drug }}=0.955, F_{\text {drug }(1,60)}=0.00318 ; P_{\text {int }}=0.847, F_{\text {int }(1,60)}=0.0375\right)$ and post-stimulation $\left(P_{\text {surg }}=0.774, F_{\text {surg }(1,60)}=0.0833\right.$; $\left.P_{\text {drug }}=0.866, F_{\text {drug }(1,60)}=0.0287 ; P_{\text {int }}=0.812, F_{\text {int }(1,60)}=0.0573\right)$ among the four groups (Figures $\mathbf{3 A}-\mathrm{C}$ ). In the STM test, no significant difference was found in the context $\left(P_{\text {surg }}=0.620\right.$, $F_{\text {surg }(1,28)}=0.251 ; P_{\text {drug }}=0.905, F_{\text {drug }(1,28)}=0.0146 ; P_{\text {int }}=0.816$, $\left.F_{\text {int }(1,28)}=0.0554\right)$ or tone test $\left(P_{\text {surg }}=0.872, F_{\text {surg }(1,28)}=0.0265\right.$; $\left.P_{\text {drug }}=0.837, F_{\text {drug }(1,28)}=0.0429 ; P_{\text {int }}=0.403, F_{\text {int }(1,28)}=0.721\right)$ among the four groups (Figure 3D). In the LTM test, the percent of freezing time in the context test decreased in the Laparotomy
+ Vehicle group compared with the Sham + Vehicle group, whereas SAHA diminished the decrease in the Laparotomy + SAHA group compared with the Laparotomy + Vehicle group $\left(P_{\text {surg }}=0.014, F_{\text {surg }(1,28)}=6.802 ; P_{\text {drug }}=0.049, F_{\text {drug }(1,28)}=4.254\right.$; $P_{\text {int }}=0.021, F_{\text {int }(1,28)}=5.991$; Figure 3E). No significant difference was observed in the tone test of LTM test among the four groups $\left(P_{\text {surg }}=0.803, F_{\operatorname{surg}(1,28)}=0.0632 ; P_{\text {drug }}=0.701\right.$, $F_{\text {drug }(1,28)}=0.150 ; P_{\text {int }}=0.898, F_{\text {int }(1,28)}=0.0167$; Figure $\left.3 E\right)$.

\section{SAHA Restored the Down-Regulation of Hippocampal Histone Acetylation in the 16-Month Old Mice Exposed to the Laparotomy} The hippocampal levels of acetyl-H3 $\left(P_{\text {surg }}=0.003\right.$, $F_{\text {surg }(1,8)}=18.703 ; P_{\text {drug }}=0.010, F_{\text {drug }(1,8)}=11.213 ; P_{\text {int }}=0.018$, $\left.F_{\text {int }(1,8)}=8.799\right)$ and acetyl-H4 $\left(P_{\text {surg }}<0.001, F_{\text {surg }(1,8)}=38.201\right.$; $\left.P_{\text {drug }}<0.001, F_{\text {drug }(1,8)}=44.448 ; P_{\text {int }}<0.001, F_{\text {int }(1,8)}=28.585\right)$ decreased in the Laparotomy + Vehicle group than those in the Sham + Vehicle group, whereas SAHA abolished the decrease in the Laparotomy + SAHA group compared with the Laparotomy + Vehicle group (Figures 4A,B). Four associated acetylation sites including acetyl-H3K9, acetylH3K14, acetyl-H4K5, and acetyl-H4K12 were analyzed. The hippocampal acetylation levels of H3K9 $\left(P_{\text {surg }}=0.005\right.$, $F_{\text {surg }(1,8)}=14.682 ; P_{\text {drug }}=0.007, F_{\text {drug }(1,8)}=12.972 ; P_{\text {int }}=0.006$, $\left.F_{\text {int }(1,8)}=13.898\right)$, H4K5 $\left(P_{\text {surg }}<0.001, F_{\text {surg }(1,8)}=29.653\right.$; $\left.P_{\text {drug }}=0.003, F_{\text {drug }(1,8)}=17.851 ; P_{\text {int }}=0.002, F_{\text {int }(1,8)}=20.698\right)$, and H4K12 $\left(P_{\text {surg }}<0.001, F_{\text {surg }(1,8)}=40.116 ; P_{\text {drug }}=0.002\right.$, 

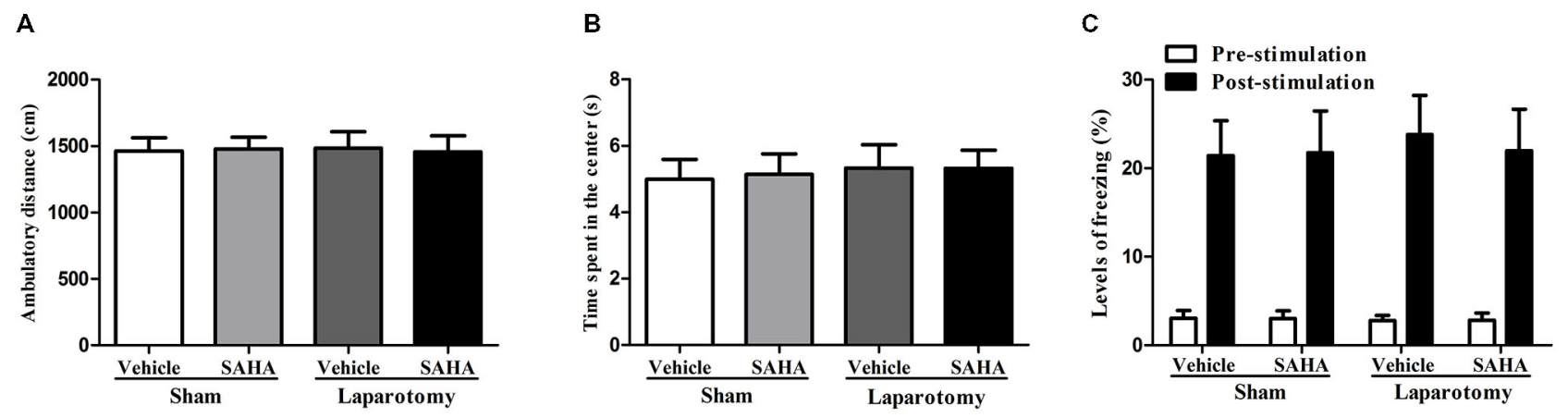

D 2-hour

E

24-hour
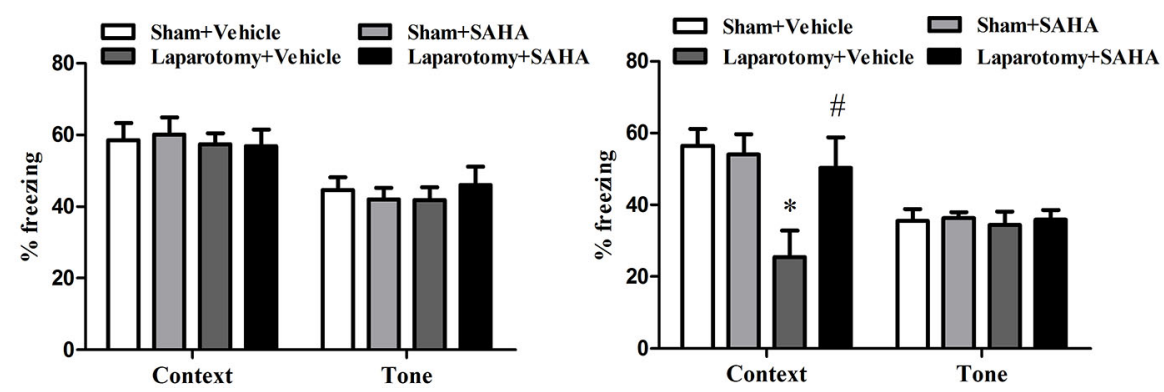

FIGURE 3 | Impact of suberoylanilide hydroxamic acid (SAHA) treatment on the cognitive performance in the 16-month old mice after surgery. (A,B) Performance of total distance traveled and time spent in the center during the open field test. Data are presented as the mean \pm S.E.M. $(n=16)$. (C) Performance of freezing time during the fear conditioning training session. Data are presented as the mean \pm S.E.M. ( $n=16)$. (D,E) Performance during the fear conditioning tests 2 - or $24-\mathrm{h}$ after laparotomy. Data are presented as the mean \pm S.E.M. $(n=8) .{ }^{*} p<0.05$ compared with the Sham + Vehicle group; ${ }^{\#} p<0.05$ compared with the Laparotomy + Vehicle group.

$\left.F_{\text {drug(1,8) }}=19.008 ; P_{\text {int }}<0.001, F_{\text {int }(1,8)}=26.543\right)$ decreased in the Laparotomy + Vehicle group compared with the Sham + Vehicle group, whereas SAHA blocked the decreases in the Laparotomy + SAHA group compared with the Laparotomy + Vehicle group (Figures 4A,B). No significant difference was observed in the level of acetyl-H3K14 among the four groups $\left(P_{\text {surg }}=0.169, F_{\text {surg }(1,8)}=2.288 ; P_{\text {drug }}=0.588, F_{\text {drug }(1,8)}=0.319\right.$; $P_{\text {int }}=0.829, F_{\text {int }(1,8)}=0.0501 ;$ Figures 4 A,B $)$.

\section{SAHA Prevented the Dysregulation of Hippocampal Neuroapoptosis- and Synaptic Plasticity-Related Proteins in the 16-Month Old Mice Exposed to the Laparotomy}

The hippocampal protein levels of cleaved caspase$3\left(P_{\text {surg }}<0.001, F_{\text {surg }(1,8)}=49.285 ; \quad P_{\text {drug }}<0.001\right.$, $\left.F_{\text {drug }(1,8)}=37.549 ; P_{\text {int }}<0.001, F_{\text {int }(1,8)}=38.197\right)$ and iNOS $\left(P_{\text {surg }}=0.038, F_{\text {surg }(1,8)}=6.139 ; P_{\text {drug }}=0.036, F_{\text {drug }(1,8)}=6.356\right.$; $\left.P_{\text {int }}=0.015, F_{\text {int }(1,8)}=9.508\right)$ increased in the Laparotomy + Vehicle group compared with the Sham + Vehicle group, whereas SAHA eliminated the increases in the Laparotomy + SAHA group compared with the Laparotomy + Vehicle group (Figure 5A). The hippocampal protein levels of BDNF $\left(P_{\text {surg }}=0.010, F_{\text {surg }(1,8)}=11.409 ; P_{\text {drug }}=0.007, F_{\text {drug }(1,8)}=13.191\right.$; $\left.P_{\text {int }}=0.006, F_{\text {int }(1,8)}=13.434\right)$, synapsin $1\left(P_{\text {surg }}=0.039\right.$, $F_{\text {surg }(1,8)}=6.070 ; P_{\text {drug }}=0.049, F_{\text {drug }(1,8)}=5.387 ; P_{\text {int }}=0.035$,
$\left.F_{\text {int }(1,8)}=6.418\right)$, and PSD95 $\left(P_{\text {surg }}=0.024, F_{\text {surg }(1,8)}=7.708\right.$; $\left.P_{\text {drug }}=0.060, F_{\text {drug }(1,8)}=4.786 ; P_{\text {int }}=0.069, F_{\text {int }(1,8)}=4.401\right)$ decreased in the Laparotomy + Vehicle group compared with the Sham + Vehicle group, whereas SAHA reversed the decreases in the Laparotomy + SAHA group compared with the Laparotomy + Vehicle group (Figure 5B).

The hippocampal NR2A $\left(P_{\text {surg }}=0.007, F_{\text {surg }(1,8)}=12.823\right.$; $\left.P_{\text {drug }}=0.048, F_{\text {drug }(1,8)}=5.428 ; P_{\text {int }}=0.029, F_{\text {int }(1,8)}=7.055\right)$, NR2B $\left(P_{\text {surg }}<0.001, F_{\text {surg }(1,8)}=26.202 ; P_{\text {drug }}=0.025\right.$, $\left.F_{\text {drug }(1,8)}=7.533 ; P_{\text {int }}=0.037, F_{\text {int }(1,8)}=6.217\right)$, CaMKII $\alpha$ $\left(P_{\text {surg }}<0.001, \quad F_{\text {surg }(1,8)}=28.352 ; \quad P_{\text {drug }}=0.007\right.$, $\left.F_{\text {drug }(1,8)}=12.744 ; \quad P_{\text {int }}<0.001, \quad F_{\text {int }(1,8)}=27.711\right)$, and CaMKII $\beta\left(P_{\text {surg }}=0.037, F_{\text {surg }(1,8)}=6.203 ; P_{\text {drug }}=0.020\right.$, $\left.F_{\text {drug }(1,8)}=8.463 ; P_{\text {int }}=0.029, F_{\text {int }(1,8)}=7.001\right)$ were up-regulated in the Laparotomy +Vehicle group compared with the Sham + Vehicle group, whereas SAHA inhibited the up-regulation in the Laparotomy + SAHA group compared with the Laparotomy + Vehicle group (Figure 6). The gene expression level changes at the protein level measured by western blot were consistent to those at mRNA level measured by RT-real time PCR (Figure 7). The statistical results were as follows: iNOS $\left(P_{\text {surg }}<0.001\right.$, $F_{\text {surg }(1,8)}=89.695 ; \quad P_{\text {drug }}<0.001, \quad F_{\text {drug }(1,8)}=50.714 ;$ $\left.P_{\text {int }}<0.001, F_{\text {int }(1,8)}=39.864\right), \operatorname{BDBF}\left(P_{\text {surg }}=0.019\right.$, $F_{\text {surg }(1,8)}=8.523 ; P_{\text {drug }}=0.256, F_{\text {drug }(1,8)}=1.499 ; P_{\text {int }}=0.019$, $\left.F_{\text {int }(1,8)}=8.523\right)$, synapsin $1\left(P_{\text {surg }}=0.013, F_{\text {surg }(1,8)}=10.257\right.$; $\left.P_{\text {drug }}=0.030, F_{\text {drug }(1,8)}=6.956 ; P_{\text {int }}=0.021, F_{\text {int }(1,8)}=8.254\right)$, 

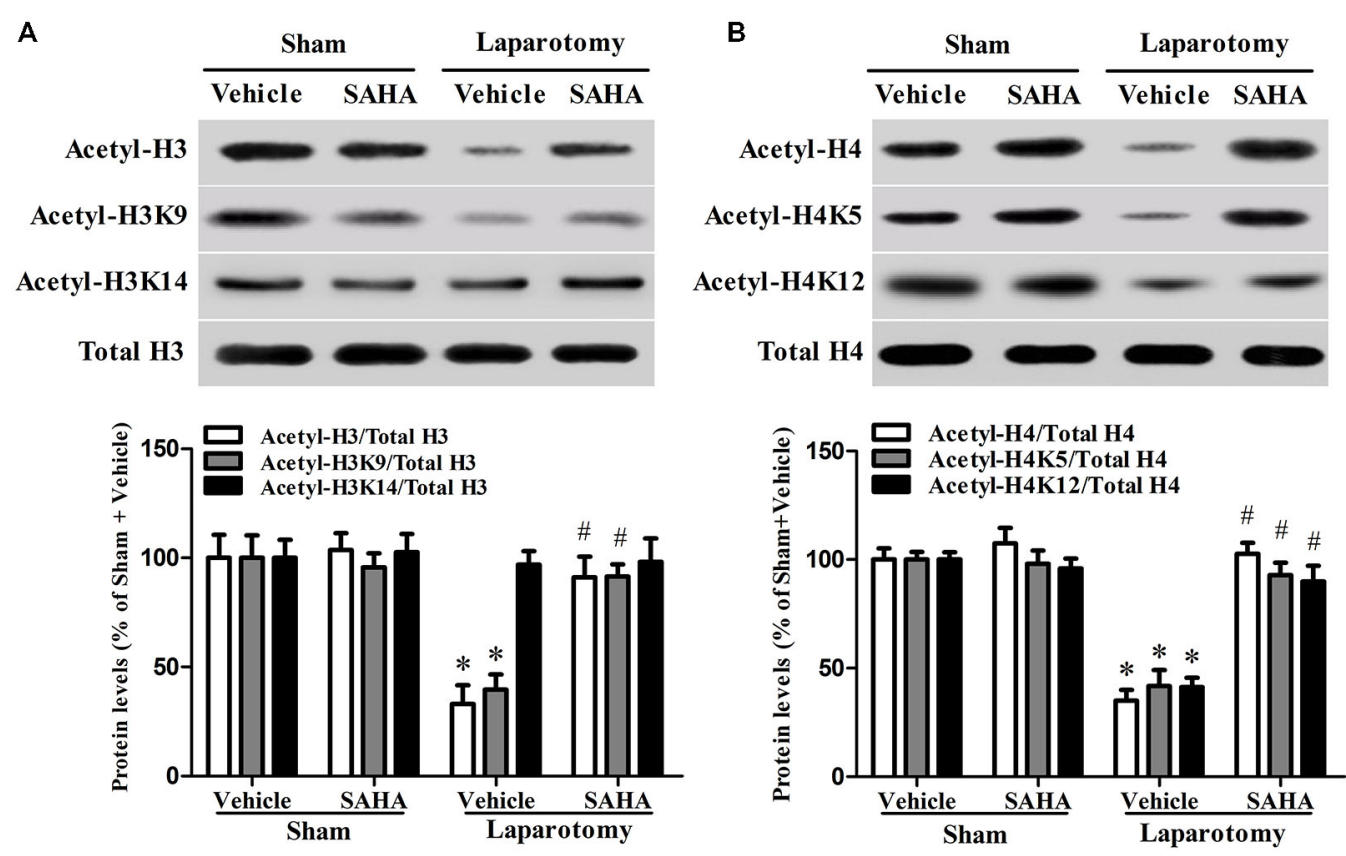

FIGURE 4 | Impact of SAHA treatment on the level of histone acetylation in the 16-month old mice after surgery. (A) The representative blot of histone H3 acetylation is shown at the top of the panel and the corresponding quantitative result is shown at the bottom. Data are presented as the mean $\pm \mathrm{S}$. E.M. $(n=3)$. (B) The representative blot of histone $\mathrm{H} 4$ acetylation is shown at the top of the panel and the corresponding quantitative result is shown at the bottom. Data are presented as the mean \pm S.E.M. $(n=3) .{ }^{*} p<0.05$ compared with the Sham + Vehicle group; ${ }^{*} p<0.05$ compared with the Laparotomy + Vehicle group.

PSD95 $\left(P_{\text {surg }}=0.003, F_{\text {surg }(1,8)}=16.908 ; P_{\text {drug }}=0.004\right.$, $\left.F_{\text {drug }(1,8)}=15.535 ; P_{\text {int }}=0.033, F_{\text {int }(1,8)}=6.646\right)$, CaMKII $\beta$ $\left(P_{\text {surg }}=0.037, F_{\text {surg }(1,8)}=6.203 ; P_{\text {drug }}=0.020, F_{\text {drug }(1,8)}=8.463\right.$; $\left.P_{\text {int }}=0.029, F_{\text {int }(1,8)}=7.001\right), \quad \mathrm{NR} 2 \mathrm{~A}\left(P_{\text {surg }}<0.001\right.$, $F_{\text {surg }(1,8)}=27.121 ; P_{\text {drug }}=0.021, F_{\text {drug }(1,8)}=8.224 ; P_{\text {int }}=0.037$, $\left.F_{\text {int }(1,8)}=6.253\right), \quad \mathrm{NR} 2 \mathrm{~B}\left(P_{\text {surg }}<0.001, F_{\text {surg }(1,8)}=43.819\right.$; $\left.P_{\text {drug }}=0.002, F_{\text {drug }(1,8)}=21.952 ; P_{\text {int }}=0.002, F_{\text {int }(1,8)}=20.371\right)$, CaMKII $\alpha\left(P_{\text {surg }}<0.001, F_{\text {surg }(1,8)}=64.159 ; P_{\text {drug }}<0.001\right.$, $\left.F_{\text {drug(1,8) }}=31.208 ; P_{\text {int }}<0.001, F_{\text {int }(1,8)}=47.622\right)$, and CaMKII $\beta\left(P_{\text {surg }}<0.001, F_{\text {surg }(1,8)}=65.655 ; P_{\text {drug }}<0.001\right.$, $\left.F_{\text {drug }(1,8)}=25.505 ; P_{\text {int }}<0.001, F_{\text {int }(1,8)}=39.780\right)$.

\section{Discussion}

In the present study, we found that the laparotomy-induced hippocampus-dependent LTM impairments were accompanied by the decreased acetylation levels of hippocampal histone $\mathrm{H} 3$ and H4 in 16- but not 3-month old mice. Treatment with SAHA rescued the histone acetylation levels and ameliorated the hippocampus-dependent LTM impairments in 16-month old mice exposed to the laparotomy.

Studies have revealed many risk factors, including advanced age, poor education, duration of anesthesia, respiratory complications, severity of coexisting illness, and psychoactive drugs, contributing to the development of POCD (Moller et al., 1998; Wan et al., 2007). Of these, advanced age is regarded as the prominent risk factor for the occurrence and development of POCD (Moller et al., 1998; Wan et al., 2007; Fidalgo et al., 2011). Therefore, aging animals were used to establish the relevant POCD models (Rosczyk et al., 2008; Li et al., 2014). We showed that 3-month old mice exposed to the laparotomy had no cognitive deficits, but 16-month old mice had the hippocampal LTM impairments, suggesting that the laparotomy can induce age-related behavioral impairments. Moreover, the context-dependent associative memory serves as an indicative of hippocampus-dependent associative memory and the tone-dependent associative memory requires proper function of amygdala (Barrientos et al., 2012). Thus, the impaired hippocampal LTM in 16- but not 3-month old mice indicated that the deteriorating effects of the laparotomy on the cognitive function are age-related. Similar to previous studies (Rosczyk et al., 2008; Li et al., 2014), we also did not observe an impaired STM in the 3- or 16-month old mice, which indicated that the model of POCD used in this study unaffected the intact STM.

Epigenetics have been shown to be deeply involved in the learning and memory deficits in neurodegenerative diseases (Govindarajan et al., 2011; Haettig et al., 2011; Haberman et al., 2012), whose phenotypes and pathogenesis are similar to POCD (Wang et al., 2013; Luo et al., 2014; Xu et al., 2014). However, the role of epigenetics in the development of POCD remains to be investigated. In our study, the decreased levels of hippocampal histone $\mathrm{H} 3$ and $\mathrm{H} 4$ acetylation and the impaired cognition in the 16-month old mice exposed to the laparotomy were prevented by the SAHA treatment, which suggested that the down-regulation of hippocampal acetyl-H3 and acetyl-H4 contributes to the pathogenesis of POCD. Moreover, SAHA did not up-regulate the histone acetyl-H3 and acetyl-H4 in the mice exposed to the sham surgery compared with those exposed to the laparotomy, 
A

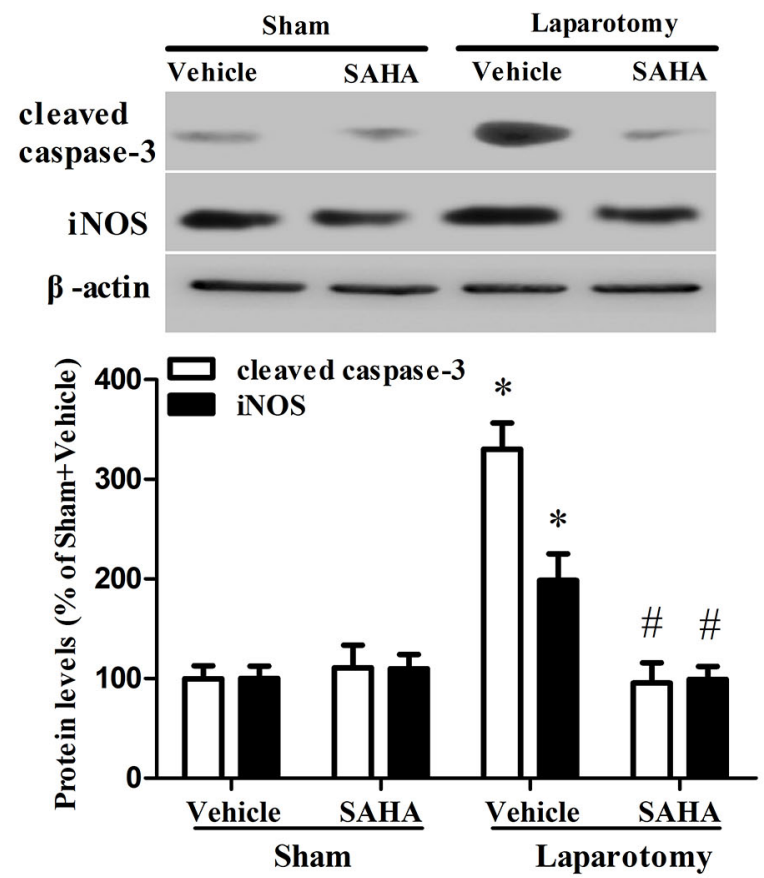

B

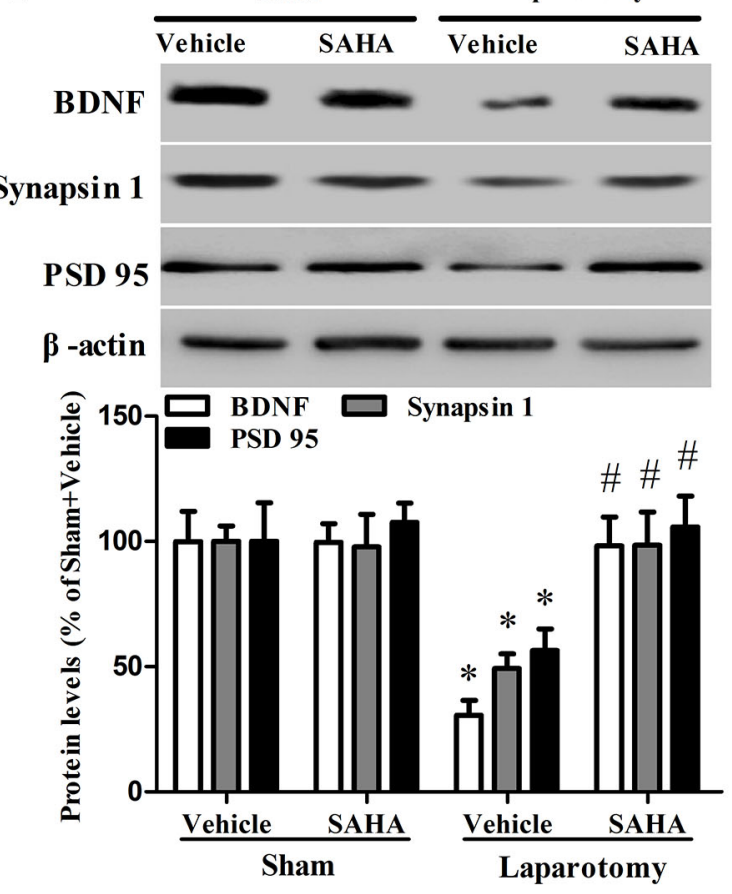

FIGURE 5 | Impact of SAHA treatment on protein expressions of cleaved caspase-3, iNOS, BDNF, synapsin 1 and PSD95 in the 16-month old mice after surgery. (A) The protein levels of cleaved caspase-3 and iNOS were determined by western blot. Representative image is at the top and quantitative result is at the bottom. Data are presented as the mean \pm S.E.M. $(n=3)$. (B) The result of western blot for BDNF, synapsin 1, and PSD95. Representative image is shown at the top and quantitation is at the bottom. Data are presented as the mean \pm S.E.M. $(n=3) .{ }^{*} p<0.05$ compared with the Sham + Vehicle group; ${ }^{\#} p<0.05$ compared with the Laparotomy + Vehicle group.

which indicated that the over activity of HDAC makes it more sensitive to SAHA. Previous studies have revealed that not all lysines in histone proteins are affected in the development of neurodegenerative disorders (Miao et al., 2014; Zhong et al., 2014) and different diseases induce histone acetylation level changes at different sites (Guan et al., 2009; Itzhak et al., 2013). Our results showed that the laparotomy induced histone acetylation level changes at the sites of $\mathrm{H} 3 \mathrm{~K} 9, \mathrm{H} 4 \mathrm{~K} 5$, and $\mathrm{H} 4 \mathrm{~K} 12$, but not $\mathrm{H} 3 \mathrm{~K} 14$, which suggested that investigating these specific acetylation sites would be helpful to further understand the potential pathogenesis of POCD.

To clarify how the altered histone acetylation leads to the laparotomy-induced cognitive deficits, we investigated the expression of proteins related to cognition performance in 16month old mice. Studies have linked the increased histone acetylation in the hippocampus to memory permissive for the transcription of learning-related plasticity genes (Ravi and Kannan, 2013) and attributed neuron damages and synaptic plasticity changes to the development of POCD (Bozon et al., 2002; Jungwirth et al., 2009; Cibelli et al., 2010; Lin and Zuo, 2011). We observed that neuroapoptosis-related proteins cleaved caspase- 3 and iNOS were up-regulated, and synaptic plasticity-related proteins BDNF, synapsin 1, and PSD95 were down-regulated in the 16-month old mice after the laparotomy.
NMDAR and CaMKII proteins mainly locate at hippocampus and prefrontal cortex and play critical roles in learning and memory (Coultrap et al., 2014). Both the aged rats after the isoflurane/nitrous oxide anesthesia and the $\mathrm{AD}$ like rats exhibit cognitive deficits and neuroapoptosis associated with an over-expression of hippocampal NR2B (Liu et al., 2012; Mawhinney et al., 2012). In aged mice, a higher expression of NMDAR2 was associated with poorer memory (Zhao et al., 2009). Therefore, our finding that the activation of NMDAR2-CaMKII pathway was observed in the hippocampus of 16-month old mice exposed to the laparotomy might correspond to their memory deficits. It was well studied that extra-synaptic NMDARs interfered with the BDNF expression, shut off cell survival pathway, induced mitochondrial dysfunction and activated pro-death molecules (Hardingham et al., 2002). Our results of reduced BDNF and increased cleaved caspase- 3 and iNOS suggested that cell death might be triggered in our aging mice with POCD. Since SAHA alleviated the up-regulation of NR2, CaMKII, cleaved caspase-3 and iNOS, it was conceivable that the pathological high expression of these molecules contributed to the development of POCD possibly by histone acetylation.

Increased histone acetylation is generally associated with a chromatin structure that is more permissive for gene transcript. 
A

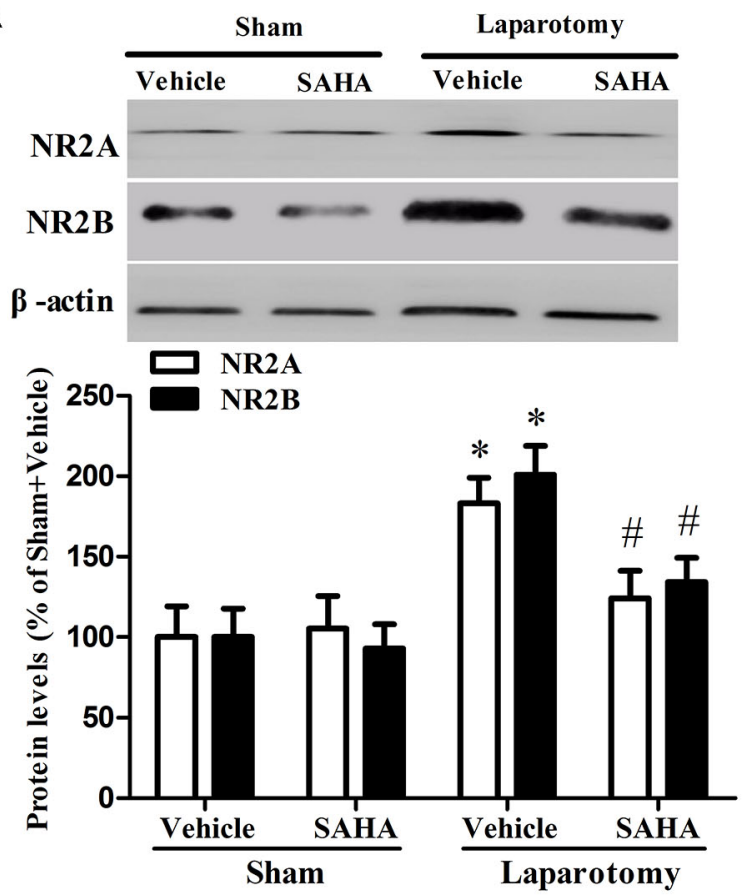

B

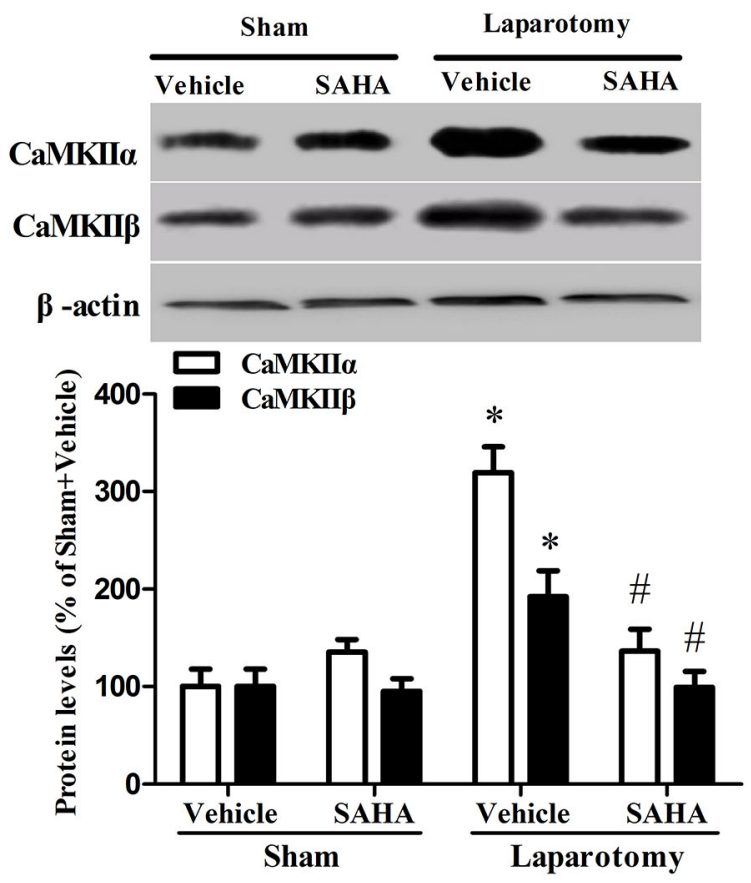

FIGURE 6 | Impact of SAHA treatment on protein expressions of NR2A, NR2B, CaMKII $\alpha$, and CaMKII $\beta$ in the 16-month old mice after surgery. (A) The protein levels of NR2A, NR2B were determined by western blot. Representative image is shown at the top and quantitative result at the bottom. Data are presented as the mean \pm S.E.M. $(n=3)$. (B) The protein levels of CaMKIl $\alpha$ and CaMKII . Representative image is shown at the top and quantitative result at the bottom. Data are presented as the mean \pm S.E.M. $(n=3) .{ }^{*} p<0.05$ compared with the Sham + Vehicle group; ${ }^{*} p<0.05$ compared with the Laparotomy + Vehicle group.

Our finding of the up-regulations of iNOS, NR2A, NR2B and CaMKII in the laparotomy with lower acetylation indicated that the expressions of these genes might not be regulated

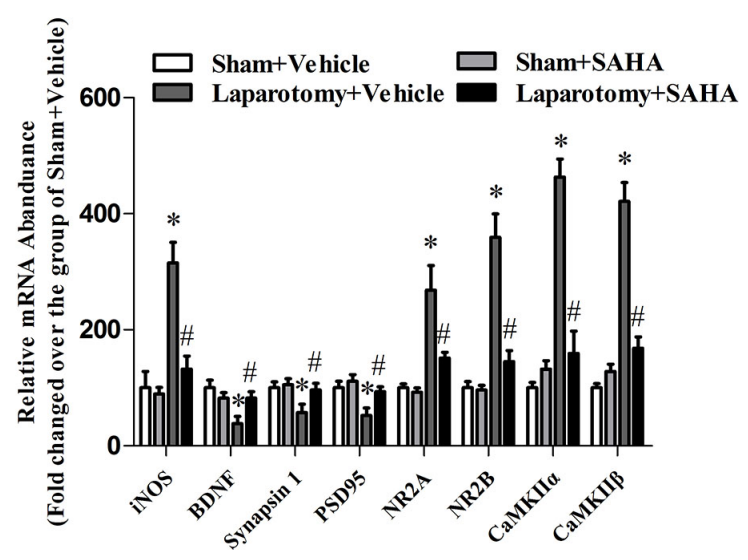

FIGURE 7 | Impact of SAHA treatment on mRNA abundances of iNOS, BDNF, synapsin 1, PSD95, NR2A, NR2B, CaMKII $\alpha$, and CaMKII $\beta$ in the 16-month old mice after surgery. The real-time PCR results were normalized by those of genes glyceraldehyde-3-phosphate dehydrogenase (GAPDH). The results from each group were then normalized by those from the group of vehicle-treated mice subjected to sham surgery. Data are presented as the mean \pm S.E.M. $(n=3) .{ }^{*} p<0.05$ compared with the Sham + Vehicle group; $\# p<0.05$ compared with the Laparotomy + Vehicle group. directly through histone acetylation on their promoters. It might have other regulation mechanisms following histone acetylation underlying these genes. While the down-regulation of BDNF, synapsin 1 and PSD 95 corresponding to the down-regulation of histone acetylation indicated that the promoters of these genes might be deacetylated by HDAC in our POCD model. Further studies on the promoters of these genes by chromatin immunoprecipitation are needed to investigate the dynamic state of histone acetylation associated with these changes of gene expressions.

It is clear that not only cardiac surgeries, but also abdominal orthopedic can also produce POCD (Martin et al., 2005). The possible reason is that immune challenge induced by the laparotomy results in an exaggerated inflammatory response in the hippocampus, a region of the brain that contains a large number of pro-inflammatory cytokine receptors, through the communication between the peripheral immune system and the brain (Parnet et al., 1994). The neuroinflammatory response in turn affect the expression of other important genes to cause cognitive dysfunction, which is associated with epigenetic changes such as histone acetylation or deacetylation. At an advanced age, the long lasting neuroinflammatory response likely plays an important role to cause hippocampal-dependent memory deficits (Maier, 2003; Barrientos et al., 2009). That explains the facts that age is the strongest risk factor for the development of POCD, and that anti-inflammatory is considered as a viable strategy to prevent POCD. Noticeably, 
if inflammation does not subside, it can contribute to the pathogenesis of disease (Vacas et al., 2013). Our findings of decreased histone acetylation in POCD provide novel insight into the pathology of POCD and important preclinical evidences supporting that SAHA may serve as a potential therapeutic agent for POCD.

\section{References}

Alarcón, J. M., Malleret, G., Touzani, K., Vronskaya, S., Ishii, S., Kandel, E. R., et al. (2004). Chromatin acetylation, memory and LTP are impaired in $\mathrm{CBP}^{+/-}$ mice: a model for the cognitive deficit in rubinstein-taybi syndrome and its amelioration. Neuron 42, 947-959. doi: 10.1016/j.neuron.2004.05.021

Amar, D., Fleisher, M., Pantuck, C. B., Shamoon, H., Zhang, H., Roistacher, N., et al. (1998). Persistent alterations of the autonomic nervous system after noncardiac surgery. Anesthesiology 89, 30-42. doi: 10.1097/00000542199807000-00008

Barrientos, R. M., Frank, M. G., Hein, A. M., Higgins, E. A., Watkins, L. R., Rudy, J. W., et al. (2009). Time course of hippocampal IL-1 beta and memory consolidation impairments in aging rats following peripheral infection. Brain Behav. Immun. 23, 46-54. doi: 10.1016/j.bbi.2008.07.002

Barrientos, R. M., Hein, A. M., Frank, M. G., Watkins, L. R., and Maier, S. F. (2012). Intracisternal interleukin-1 receptor antagonist prevents postoperative cognitive decline and neuroinflammatory response in aged rats. J. Neurosci. 32, 14641-14648. doi: 10.1523/jneurosci.2173-12.2012

Bozon, B., Davis, S., and Laroche, S. (2002). Regulated transcription of the immediate-early gene Zif268: mechanisms and gene dosage-dependent function in synaptic plasticity and memory formation. Hippocampus 12, 570-577. doi: 10.1002/hipo.10100

Castellano, J. F., Fletcher, B. R., Kelley-Bell, B., Kim, D. H., Gallagher, M., and Rapp, P. R. (2012). Age-related memory impairment is associated with disrupted multivariate epigenetic coordination in the hippocampus. PLoS One 7:e33249. doi: 10.1371/journal.pone.0033249

Chuang, D. M., Leng, Y., Marinova, Z., Kim, H. J., and Chiu, C. T. (2009). Multiple roles of HDAC inhibition in neurodegenerative conditions. Trends Neurosci. 32, 591-601. doi: 10.1016/j.tins.2009.06.002

Cibelli, M., Fidalgo, A. R., Terrando, N., Ma, D., Monaco, C., Feldmann, M., et al. (2010). Role of interleukin-1beta in postoperative cognitive dysfunction. Ann. Neurol. 68, 360-368. doi: 10.1002/ana.22082

Coultrap, S. J., Freund, R. K., O'Leary, H., Sanderson, J. L., Roche, K. W., Dell'Acqua, M. L., et al. (2014). Autonomous CaMKII mediates both LTP and LTD using a mechanism for differential substrate site selection. Cell Rep. 6, 431-437. doi: 10.1016/j.celrep.2014.01.005

Dash, P. K., Orsi, S. A., Zhang, M., Grill, R. J., Pati, S., Zhao, J., et al. (2010). Valproate administered after traumatic brain injury provides neuroprotection and improves cognitive function in rats. PLoS One 5:e11383. doi: 10. 1371/journal.pone.0011383

Feng, C., Cao, L., and Zuo, Z. (2011). RNA interference-produced autoregulation of inducible nitric oxide synthase expression. FEBS Lett. 585, 2488-2492. doi: 10.1016/j.febslet.2011.06.032

Fidalgo, A. R., Cibelli, M., White, J. P., Nagy, I., Maze, M., and Ma, D. (2011). Systemic inflammation enhances laparotomy surgery-induced cognitive dysfunction in mice. Neurosci. Lett. 498, 63-66. doi: 10.1016/j.neulet. 2011.04.063

Fischer, A., Sananbenesi, F., Mungenast, A., and Tsai, L. H. (2010). Targeting the correct HDAC (s) to treat cognitive disorders. Trends Pharmacol. Sci. 31, 605-617. doi: 10.1016/j.tips.2010.09.003

Francis, Y. I., Fà, M., Ashraf, H., Zhang, H., Staniszewski, A., Latchman, D. S., et al. (2009). Dysregulation of histone acetylation in the APP/PS1 mouse model of Alzheimer's disease. J. Alzheimers Dis. 18, 131-139. doi: 10.3233/JAD-20091134

Govindarajan, N., Agis-Balboa, R. C., Walter, J., Sananbenesi, F., and Fischer, A. (2011). Sodium butyrate improves memory function in an Alzheimer's disease mouse model when administered at an advanced stage of disease progression. J. Alzheimers Dis. 26, 187-197. doi: 10.3233/JAD-2011-110080

\section{Acknowledgments}

This work was supported by National Natural Science Foundation of China (Nos. 81271216, 81300946, 81300262, and 81471105$)$ and Natural Science Foundation of Jiangsu Province (No. BK2012778).

Gräff, J., and Tsai, L. H. (2013). The potential of HDAC inhibitors as cognitive enhancers. Annu. Rev. Pharmacol. Toxicol. 53, 311-330. doi: 10.1146/annurevpharmtox-011112-140216

Guan, J. S., Haggarty, S. J., Giacometti, E., Dannenberg, J. H., Joseph, N., Gao, J., et al. (2009). HDAC2 negatively regulates memory formation and synaptic plasticity. Nature 459, 55-60. doi: 10.1038/nature07925

Haberman, R. P., Quigley, C. K., and Gallagher, M. (2012). Characterization of $\mathrm{CpG}$ island DNA methylation of impairment-related genes in a rat model of cognitive aging. Epigenetics 7, 1008-1009. doi: 10.4161/epi. 21291

Haettig, J., Stefanko, D. P., Multani, M. L., Figueroa, D. X., McQuown, S. C., and Wood, M. A. (2011). HDAC inhibition modulates hippocampus-dependent long-term memory for object location in a CBP-dependent manner. Learn. Mem. 18, 71-79. doi: 10.1101/lm.1986911

Haggarty, S. J., and Tsai, L. H. (2011). Probing the role of HDACs and mechanisms of chromatin-mediated neuroplasticity. Neurobiol. Learn. Mem. 96, 41-52. doi: 10.1016/j.nlm.2011.04.009

Hardingham, G. E., Fukunaga, Y., and Bading, H. (2002). Extrasynaptic NMDARs oppose synaptic NMDARs by triggering CREB shut-off and cell death pathways. Nat. Neurosci. 5, 405-414. doi: 10.1038/nn835

Hovens, I. B., Schoemaker, R. G., van der Zee, E. A., Heineman, E., Izaks, G. J., and van Leeuwen, B. L. (2012). Thinking through postoperative cognitive dysfunction: how to bridge the gap between clinical and pre-clinical perspectives. Brain Behav. Immun. 26, 1169-1179. doi: 10.1016/j.bbi.2012. 06.004

Hovens, I. B., van Leeuwen, B. L., Nyakas, C., Heineman, E., van der Zee, E. A., and Schoemaker, R. G. (2014). Postoperative cognitive dysfunction and microglial activation in associated brain regions in old rats. Neurobiol. Learn. Mem. 118, 74-79. doi: 10.1016/j.nlm.2014.11.009

Itzhak, Y., Liddie, S., and Anderson, K. L. (2013). Sodium butyrate-induced histone acetylation strengthens the expression of cocaine-associated contextual memory. Neurobiol. Learn. Mem. 102, 34-42. doi: 10.1016/j.nlm.2013. 03.007

Ji, M., Dong, L., Jia, M., Liu, W., Zhang, M., Ju, L., et al. (2014). Epigenetic enhancement of brain-derived neurotrophic factor signaling pathway improves cognitive impairments induced by isoflurane exposure in aged rats. Mol. Neurobiol. 50, 937-944. doi: 10.1007/s12035-014-8659-Z

Jungwirth, B., Zieglgänsberger, W., Kochs, E., and Rammes, G. (2009). Anesthesia and postoperative cognitive dysfunction (POCD). Mini. Rev. Med. Chem. 9, 1568-1579. doi: 10.2174/138955709791012229

Kazantsev, A. G., and Thompson, L. M. (2008). Therapeutic application of histone deacetylase inhibitors for central nervous system disorders. Nat. Rev. Drug. Discov. 7, 854-868. doi: 10.1038/nrd2681

Kilgore, M., Miller, C. A., Fass, D. M., Hennig, K. M., Haggarty, S. J., Sweatt, J. D., et al. (2010). Inhibitors of class 1 histone deacetylases reverse contextual memory deficits in a mouse model of Alzheimer's disease. Neuropsychopharmacology 35, 870-880. doi: 10.1038/npp.2009.197

Lin, D., and Zuo, Z. (2011). Isoflurane induces hippocampal cell injury and cognitive impairments in adult rats. Neuropharmacology 61, 1354-1359. doi: 10.1016/j.neuropharm.2011.08.011

Liu, Z., Lv, C., Zhao, W., Song, Y., Pei, D., and Xu, T. (2012). NR2Bcontaining NMDA receptors expression and their relationship to apoptosis in hippocampus of Alzheimer's disease-like rats. Neurochem. Res. 37, 1420-1427. doi: 10.1007/s11064-012-0726-0

Li, X. M., Zhou, M. T., Wang, X. M., Ji, M. H., Zhou, Z. Q., and Yang, J. J. (2014). Resveratrol pretreatment attenuates the isoflurane-induced cognitive impairment through its anti-inflammation and -apoptosis actions in aged mice. J. Mol. Neurosci. 52, 286-293. doi: 10.1007/s12031-013-0141-2 
Luo, X., Yang, L., Chen, X., and Li, S. (2014). Tau hyperphosphorylation: a downstream effector of isoflurane-induced neuroinflammation in aged rodents. Med. Hypotheses 82, 94-96. doi: 10.1016/j.mehy.2013.11.015

Maier, S. F. (2003). Bi-directional immune-brain communication: implications for understanding stress, pain, and cognition. Brain Behav. Immun. 17, 69-85. doi: 10.1016/s0889-1591(03)00032-1

Martin, T. J., Kahn, W. R., and Eisenach, J. C. (2005). Abdominal surgery decreases food-reinforced operant responding in rats: relevance of incisional pain. Anesthesiology 103, 629-637. doi: 10.1097/00000542-200509000-00028

Mawhinney, L. J., de Rivero Vaccari, J. P., Alonso, O. F., Jimenez, C. A., Furones, C., Moreno, W. J., et al. (2012). Isoflurane/nitrous oxide anesthesia induces increases in NMDA receptor subunit NR2B protein expression in the aged rat brain. Brain Res. 1431, 23-34. doi: 10.1016/j.brainres.2011.11.004

McQuown, S. C., Barrett, R. M., Matheos, D. P., Post, R. J., Rogge, G. A., Alenghat, T., et al. (2011). HDAC3 is a critical negative regulator of long-term memory formation. J. Neurosci. 31, 764-774. doi: 10.1523/JNEUROSCI.5052-10.2011

Miao, F., Chen, Z., Genuth, S., Paterson, A., Zhang, L., Wu, X., et al. (2014). Evaluating the role of epigenetic histone modifications in the metabolic memory of type 1 diabetes. Diabetes 63, 1748-1762. doi: 10.2337/db13-1251

Moller, J. T., Cluitmans, P., Rasmussen, L. S., Houx, P., Rasmussen, H., Canet, J., et al. (1998). Long-term postoperative cognitive dysfunction in the elderly: ISPOCD1 study. Lancet 351, 857-861. doi: 10.1016/s0140-6736(97)07382-0

Parnet, P., Amindari, S., Wu, C., Brunke-Reese, D., Goujon, E., Weyhenmeyer, J. A., et al. (1994). Expression of type I and type II interleukin-1 receptors in mouse brain. Brain Res. Mol. Brain Res. 27, 63-70. doi: 10.1016/0169$328 x(94) 90185-6$

Peleg, S., Sananbenesi, F., Zovoilis, A., Burkhardt, S., Bahari-Javan, S., AgisBalboa, R. C., et al. (2010). Altered histone acetylation is associated with age-dependent memory impairment in mice. Science 328, 753-756. doi: 10. 1126/science. 1186088

Petrij, F., Giles, R. H., Dauwerse, H. G., Saris, J. J., Hennekam, R. C., Masuno, M., et al. (1995). Rubinstein-Taybi syndrome caused by mutations in the transcriptional co-activator CBP. Nature 376, 348-351. doi: 10.1038/376348a0

Ravi, B., and Kannan, M. (2013). Epigenetics in the nervous system: an overview of its essential role. Indian J. Hum. Genet. 19, 383-391. doi: 10.4103/0971-6866. 124357

Ricobaraza, A., Cuadrado-Tejedor, M., Pérez-Mediavilla, A., Frechilla, D., Del Río, J., and García-Osta, A. (2009). Phenylbutyrate ameliorates cognitive deficit and reduces tau pathology in an Alzheimer's disease mouse model. Neuropsychopharmacology 34, 1721-1732. doi: 10.1038/npp.2008.229
Rosczyk, H. A., Sparkman, N. L., and Johnson, R. W. (2008). Neuroinflammation and cognitive function in aged mice following minor surgery. Exp. Gerontol. 43, 840-846. doi: 10.1016/j.exger.2008.06.004

Terrando, N., Brzezinski, M., Degos, V., Eriksson, L. I., Kramer, J. H., Leung, J. M., et al. (2011). Perioperative cognitive decline in the aging population. Mayo Clin. Proc. 86, 885-893. doi: 10.4065/mcp.2011.0332

Vacas, S., Degos, V., Feng, X., and Maze, M. (2013). The neuroinflammatory response of postoperative cognitive decline. Br. Med. Bull. 106, 161-178. doi: 10.1093/bmb/ldt006

Wan, Y., Xu, J., Ma, D., Zeng, Y., Cibelli, M., and Maze, M. (2007). Postoperative impairment of cognitive function in rats: a possible role for cytokine-mediated inflammation in the hippocampus. Anesthesiology 106, 436-443. doi: 10 1097/00000542-200703000-00007

Wang, Y., Chen, Z., Zhao, Y., Shi, R., Wang, Y., Xu, J., et al. (2013). Epigenetics as a new therapeutic target for postoperative cognitive dysfunction. Med. Hypotheses 80, 249-251. doi: 10.1016/j.mehy.2012.11.041

Xu, Z., Dong, Y., Wang, H., Culley, D. J., Marcantonio, E. R., Crosby, G., et al. (2014). Age-dependent postoperative cognitive impairment and Alzheimerrelated neuropathology in mice. Sci. Rep. 4:3766. doi: 10.1038/srep03766

Zhao, X., Rosenke, R., Kronemann, D., Brim, B., Das, S. R., Dunah, A. W., et al. (2009). The effects of aging on N-methyl-D-aspartate receptor subunits in the synaptic membrane and relationships to long-term spatial memory. Neuroscience 162, 933-945. doi: 10.1016/j.neuroscience.2009. 05.018

Zhong, T., Qing, Q. J., Yang, Y., Zou, W. Y., Ye, Z., Yan, J. Q., et al. (2014). Repression of contexual fear memory induced by isoflurane is accompanied by reduction in histone acetylation and rescued by sodium butyrate. Br. J. Anaesth. 113, 634-643. doi: 10.1093/bja/aeu184

Conflict of Interest Statement: The authors declare that the research was conducted in the absence of any commercial or financial relationships that could be construed as a potential conflict of interest.

Copyright (c) $2015 \mathrm{Jia}, \mathrm{Liu}$, Sun, Chang, Yang, Ji, Yang and Feng. This is an openaccess article distributed under the terms of the Creative Commons Attribution License (CC BY). The use, distribution and reproduction in other forums is permitted, provided the original author(s) or licensor are credited and that the original publication in this journal is cited, in accordance with accepted academic practice. No use, distribution or reproduction is permitted which does not comply with these terms. 